\title{
Variation in Resource Utilization for Patients With Hip and Pelvic Fractures Despite Equal Medicare Reimbursement
}

\author{
Andre M. Samuel BBA, Matthew L. Webb AB, Adam M. Lukasiewicz MSc, \\ Bryce A. Basques MD, MHS, Daniel D. Bohl MD, MPH, Arya G. Varthi MD, \\ Joseph M. Lane MD, Jonathan N. Grauer MD
}

Received: 13 September 2015/Accepted: 17 February 2016/Published online: 25 February 2016

(C) The Association of Bone and Joint Surgeons \& 2016

\begin{abstract}
Background Medicare currently reimburses hospitals for inpatient admissions with "bundled" payments based on patient Diagnosis-related Groups (DRGs) regardless of true hospital costs. At present, DRG 536 (fractures of the hip and pelvis) includes a broad spectrum of patients with orthopaedic trauma, likely with varying inpatient resource utilization. With the growing incidence of fractures in the elderly, inadequate reimbursements from Medicare for certain patients with DRG 536 may lead to growing
\end{abstract}

One of the authors certifies that he (AMS) or a member of his or her immediate family, has received or may receive payments or benefits, during the study period, an amount of less than USD 10,000 from Orthopaedic Trauma Association (Rosemont, IL).

One of the authors certifies that he (JML) or a member of his or her immediate family, has received or may receive payments or benefits, during the study period, an amount of less than USD 10,000 from Bone Therapeutics (Charleroi, Belgium), an amount of less than USD 10,000 from Kuros (Zurich,Switzerland), an amount of less than USD 10,000 from ISTO Technologies (St Louis, MO, USA), an amount of less than USD 10,000 from Emcyte (Fort Myers, FL, USA), an amount of less than USD 10,000 from Royal Marketing Inc (Westmount, Quebec, Canada), an amount of less than USD 10,000 from Graftys (Chicago, IL, USA), an amount of USD 100,000-USD 1,000,000 from Merck (Kenilworth, NJ, USA), and an amount of USD 100,000-USD 1,000,000 from National Institutes of Health (Bethesda, MD, USA).

One of the authors certifies that he (JNG) or a member of his or her immediate family, has received or may receive payments or benefits, during the study period, an amount of USD 10,000-USD 100,000 from Bioventus (Durham, NC, USA), an amount of USD 10,000-USD 100,000 from Harvard Clinical Research Institute (Boston, MA, USA), an amount of USD 10,000-USD 100,000 from ISTO Technologies (St Louis, MO, USA), an amount of less than USD 10,000 from Medtronic (Minneapolis, MN, USA), an amount of USD 10,000-USD 100,000 from Stryker (Kalamazoo, MI, USA), an amount of less than USD 10,000 from Affinergy (Durham, NC, USA), an amount of USD 10,000-USD 100,000 from Alphatec (Carlsbad, CA), an amount of less than USD 10,000 from DePuy (Raynham, financial strain on healthcare institutions caring for these patients with higher costs.

Questions/purposes The purposes of the study were to determine whether (1) inpatient length of stay; (2) intensive care unit stay; and (3) ventilator time differ among subpopulations with Medicare DRG 536.

Methods A total of 56,683 patients, 65 years or older, with fractures of the hip or pelvis were identified in the 2011 and 2012 National Trauma Data Bank. This clinical registry contains data on trauma cases from more than 900 participating trauma centers, allowing analysis of resource

MA, USA), an amount of less than USD 10,000 from Powered Research (Research Triangle Park, NC, USA), an amount of less than USD 10,000 from KCI (San Antonio, TX, USA), an amount of less than USD 10,000 from Transgenomic (Omaha, NE, USA), an amount of less than USD 10,000 from Smith and Nephew (Andover, MA, USA), an amount of less than USD 10,000 from Andante Medical Devices (White Plains, NY, USA), and an amount of less than USD 10,000 from Orthopaedic Trauma Association (Rosemont, IL, USA). All ICMJE Conflict of Interest Forms for authors and Clinical Orthopaedics and Related Research ${ }^{\mathbb{B}}$ editors and board members are on file with the publication and can be viewed on request.

This work was performed at Yale School of Medicine, New Haven, CT, USA.

A. M. Samuel, M. L. Webb, A. M. Lukasiewicz, A. G. Varthi, J. N. Grauer $(\square)$

Department of Orthopaedics and Rehabilitation, Yale School of Medicine, 800 Howard Avenue, New Haven, CT 06510, USA

e-mail: jonathan.grauer@yale.edu

B. A. Basques, D. D. Bohl

Department of Orthopedic Surgery, Rush University Medical Center, Chicago, IL, USA

J. M. Lane

Department of Orthopedic Surgery, Hospital for Special Surgery, New York, NY, USA 
utilization in centers across the United States. Patients were grouped in the following subgroups: hip fractures $(\mathrm{n}=$ $35,119)$, nonoperative pelvic fractures $(n=15,506)$, acetabulum fractures, operative and nonoperative, $(\mathrm{n}=$ $7670)$, and operative pelvic fractures $(n=682)$. Total inpatient length of stay, intensive care unit (ICU) stay, and ventilator time were compared across groups using multivariate analysis that controlled for hospital factors.

Results After controlling for patient and hospital factors, difference in inpatient length of stay was -0.2 days for patients with nonoperative pelvis fractures compared with inpatient length of stay for patients with hip fractures $(95 \%$ CI, -0.4 to -0.1 days; $\mathrm{p}=0.001) ; 1.7$ days for patient with acetabulum fractures (95\% CI, 1.4-1.9 days; $\mathrm{p}<0.001$ ); and 7.7 days for patients with operative pelvic fractures (95\% CI, 7.0-8.4 days; $\mathrm{p}<0.001$ ). The difference in ICU length of stay for patients with nonoperative pelvis fractures was 0.8 days compared with ICU length of stay for patients with hip fractures (95\% CI, 0.7-0.9 days; p < $0.001)$; 1.9 days for patients with acetabulum fractures (95\% CI, 1.8-2.1 days; $\mathrm{p}<0.001$ ); and 6.3 days for patients with operative pelvic fractures (95\% CI, 5.9-6.7 days; $\mathrm{p}<0.001)$. The difference in mechanical ventilation time for patients with nonoperative fractures was 0.5 days compared with ventilation time for patients with hip fractures (95\% CI, 0.4-0.6 days; $\mathrm{p}<0.001$ ); 1.1 days for patients with acetabulum fractures (95\% CI, 1.0-1.2 days; $\mathrm{p}$ $<0.001)$; and 3.9 days for patients with operative fractures (95\% CI, 2.5-3.2 days; $\mathrm{p}<0.001$ ).

Conclusions In our current multitiered trauma system, certain centers will see higher proportions of patients with acetabulum and operative pelvic fractures. Because hospitals are reimbursed equally for these subgroups of Medicare DRG 536, centers that care for a greater proportion of patients with more-complex pelvic trauma will experience lower financial margins per trauma patient, limiting their potential for growth and investment compared with competing institutions that may not routinely see patients with high-energy trauma. Because of this, we believe reevaluation of this Medicare Prospective Payment System DRG is warranted.

Level of Evidence Level IV, economic and decision analysis.

\section{Introduction}

The current Medicare Acute Inpatient Prospective Payment System determines hospital reimbursement for inpatient admissions by categorizing patients into Diagnosis-related Groups (DRGs), originally meant to create patient classes that are "clinically consistent and that have similar patterns of output utilization" [16]. When first implemented in 1983, the DRG model represented a substantial shift away from traditional cost-based billing, transferring risk and potential cost-savings to hospitals [20]. Regardless of true hospital costs, all inpatient admissions under the same DRG are reimbursed using the same "bundled" payment, the only exception being a reimbursement modifier for either major or minor patient complications and/or comorbidities.

Although the DRG system undoubtedly has resulted in Medicare cost savings, proper division of patients in DRGs is critical to prevent under-reimbursement to hospitals or wasted Medicare payments. Under the current Medicare Severity (MS)-DRG system, MS-DRG 536 (fractures of the hip and pelvis) encompasses a large number of elderly patients with orthopaedic trauma. Although the age-adjusted incidence of fractures in elderly patients has declined since 2005, the absolute incidence has increased dramatically owing to the growing elderly population and is expected to continue to grow $[9,17]$. The U.S. population older than 85 years is expected to increase threefold between 2010 and 2050 [17]. In addition, fractures in elderly patients can be costly to manage, as they often require surgical intervention. However, the average lowenergy hip fracture and high-energy pelvic fracture, both included in DRG 536, are considerably different injuries with differing management courses and, likely, differing associated inpatient costs [10]. Owing to the common nature of these injuries, these differences in costs may account for substantial sums. Classification of other Medicare DRGs for procedures such as total joint arthroplasty, spinal fusion, and coronary artery bypass grafting has been modified to take into account cost variations [5, 7]. For example because of higher hospital costs associated with revision arthroplasty, versus primary arthroplasty, these procedures were separated into a separate DRG with greater reimbursement rates [5-7]. As the complexities of our current US healthcare environment make estimation of true healthcare costs difficult, several measures of hospital resource utilization were used as proxies for inpatient costs. In this way, differences in utilization also can be translated across health systems, regardless how cost accounting practices differ between individual institutions.

The purposes of this study were to determine whether (1) inpatient length of stay; (2) ICU stay; and (3) ventilator time differ between subpopulations with Medicare DRG 536, even after controlling for hospital factors.

\section{Materials and Methods}

A retrospective study was performed using the 2011 and 2012 American College of Surgeons National Trauma Data Bank Research Data Set. The National Trauma Data Bank 
is the largest national database of trauma cases, and includes patients from more than 900 trauma centers annually. Although other commonly studied national databases, such as the National Surgical Quality Improvement Program database, do not include patients treated nonoperatively or with high-energy trauma, the National Trauma Data Bank allows analysis of patients from centers across the US, or the full spectrum of patients in DRG 536, who were treated operatively and nonoperatively and who sustained high-energy and low-energy injuries. In addition, there currently are numerous methods used by healthcare economists and hospital administrators to calculate costs, with no consensus between institutions or researchers. The National Trauma Data Bank offers data on various measures of healthcare resource utilization, namely inpatient length of stay, ICU stay, and mechanical ventilation time, which may be used as proxies for inpatient costs. In this way, differences in utilization also can be translated across health systems, regardless of the differing cost accounting practices of individual institutions. Human investigations committee approval was acquired before initiating the study.

International Classification of Diseases, $9^{\text {th }}$ Revision (ICD-9) diagnosis codes were used to identify patients with MS-DRG 536 based on diagnoses of acetabulum fractures, including operative and nonoperative (ICD-9 808.0-808.1); other pelvic fractures (ICD-9 808.2-808.59); and hip fractures (ICD-9 820.20-820.32). Patients with other pelvic fractures were further subdivided into operative and nonoperative pelvic fracture-based ICD-9 procedure codes (ICD-9 79.19, 79.29, 79.39, or 79.49). Patients treated operatively versus nonoperatively, or with internal fixation versus arthroplasty, would similarly be grouped in MS-DRG 536 , regardless of ultimate treatment modality. Only patients in the Medicare age group (65 years or older) were included.

A retrospective study was performed comparing inpatient length of stay, intensive care unit stay, and ventilator time among the four subpopulations of Medicare DRG 536. The three resource utilization measures of interest were reported as continuous variables in the National Trauma Data Bank. Multivariate analysis controlled for possible confounding patient and hospital factors including the Charlson Comorbidity Index, hospital teaching status (university, community, or nonteaching), hospital size ( $\leq 200$ beds, $201-400$ beds, $401-600$ beds, or $>600$ beds), and geographic region (by US Census regions: Northeast, Midwest, South, and West). The modified Charlson Comorbidity Index [24] has been shown to have comparable predictive value to the original Charlson Comorbidity Index and has been used in studies of national databases [3, 4, 14]. Computation of the modified Charlson Comorbidity Index was based on National Trauma Data Bank comorbidity and age data using the same methods used in other studies $[23,24]$. The hospital factors are reported in the National Trauma Data Bank by participating institutions. Two additional possible confounding variables are month of admission and American College of Surgeons trauma center level. Previous studies $[2,21]$ have shown that length of stay may vary according to a seasonal or "July" effect and by American College of Surgeons level. Unfortunately data regarding date or month of admission are unavailable in the National Trauma Data Bank and a large amount $(36 \%)$ of data are missing for the American College of Surgeons level. However, as contributing trauma centers submit a full year of patient data to the National Trauma Data Bank, most seasonal variations can be expected to wash out. In addition, controlling for teaching status (nonteaching, community, or university) and hospital size should address much of the bias among American College of Surgeons levels.

\section{Statistical Analysis}

Multivariate linear regression was used to test the differences in outcome measures between subgroups after controlling for hospital factors. This was followed by Tukey's post hoc pairwise comparisons to test the significance of individual comparisons between the four subpopulations.

All statistical analyses were performed using Stata ${ }^{\circledR}$ Version 13.0 (StataCorp, LP, College Station, TX, USA). All statistical tests were two-tailed, and the level of significance was set at $\alpha=0.05$. All analyses were adjusted for clustering by institution.

\section{Demographics, Description of Study Population}

A total of 58,977 patients met inclusion criteria. Of those, 35,119 had hip fractures, 15,506 had nonoperative pelvic fractures, 7670 had acetabulum fractures, and 682 had operative pelvic fractures. Sex, age, Charlson Comorbidity Index, and Injury Severity Score varied predictably between groups (Table 1). Six thousand one hundred eighty patients with hip fractures $(17.6 \%$ of all hip fractures) and 307 patients with acetabular fractures $(4.0 \%$ of all acetabular fractures) were treated with arthroplasty (THA or hemiarthroplasty).

\section{Results}

Inpatient Length of Stay

Patients with operative pelvic fractures had the longest mean length of stay at 15.2 days (SD, 13.6 days) (Fig. 1). 
Table 1. Summary statistics for the patients

\begin{tabular}{|c|c|c|c|c|c|c|c|c|}
\hline \multirow{2}{*}{$\begin{array}{l}\text { Patient factors } \\
\text { Sex }\end{array}$} & \multicolumn{2}{|c|}{$\begin{array}{l}\text { Hip fracture } \\
(\mathrm{n}=35,119)\end{array}$} & \multicolumn{2}{|c|}{$\begin{array}{l}\text { Nonoperative pelvic fracture } \\
(\mathrm{n}=15,506)\end{array}$} & \multicolumn{2}{|c|}{$\begin{array}{l}\text { Acetabulum fracture } \\
(\mathrm{n}=7670)\end{array}$} & \multicolumn{2}{|c|}{$\begin{array}{l}\text { Operative pelvic fracture } \\
(\mathrm{n}=682)\end{array}$} \\
\hline & & & & & & & & \\
\hline Female & 24,046 & $68 \%$ & 11,685 & $75 \%$ & 3377 & $44 \%$ & 252 & $37 \%$ \\
\hline Male & 11,073 & $32 \%$ & 3821 & $25 \%$ & 4293 & $56 \%$ & 430 & $63 \%$ \\
\hline Age (years) & \multicolumn{2}{|c|}{$($ mean $=80)$} & \multicolumn{2}{|c|}{$($ mean $=79)$} & \multicolumn{2}{|c|}{$($ mean $=77)$} & \multicolumn{2}{|c|}{$($ mean $=73)$} \\
\hline $65-69$ & 3702 & $10 \%$ & 2002 & $13 \%$ & 1804 & $24 \%$ & 272 & $40 \%$ \\
\hline $70-74$ & 4573 & $13 \%$ & 2105 & $14 \%$ & 1437 & $19 \%$ & $150^{*}$ & $22 \% *$ \\
\hline $75-79$ & 6472 & $18 \%$ & 2773 & $18 \%$ & $1352 *$ & $18 \% *$ & 124 & $18 \%$ \\
\hline $80-84$ & $9670^{*}$ & $28 \% *$ & $4172 *$ & $27 \% *$ & 1626 & $21 \%$ & 84 & $12 \%$ \\
\hline $\begin{array}{l}85+ \\
\text { Charlson Comorbidity Index }\end{array}$ & \multicolumn{2}{|c|}{$($ mean $=5)$} & \multicolumn{2}{|c|}{$($ mean $=5)$} & \multicolumn{2}{|c|}{$($ mean $=4)$} & \multicolumn{2}{|c|}{$($ mean $=4)$} \\
\hline 3 & 2219 & $6 \%$ & 1553 & $10 \%$ & 1304 & $17 \%$ & 223 & $33 \%$ \\
\hline 4 & $16,579^{*}$ & $47 \% *$ & $8155^{*}$ & $53 \% *$ & $3498 *$ & $46 \% *$ & $303 *$ & $44 \% *$ \\
\hline 5 & 9265 & $26 \%$ & 3524 & $23 \%$ & 1739 & $23 \%$ & 101 & $15 \%$ \\
\hline $6+$ & 7056 & $20 \%$ & 2274 & $15 \%$ & 1129 & $15 \%$ & 55 & $8 \%$ \\
\hline Injury Severity Score & \multicolumn{2}{|c|}{$($ mean $=10)$} & \multicolumn{2}{|c|}{$($ mean $=11)$} & \multicolumn{2}{|c|}{$($ mean $=12)$} & \multicolumn{2}{|c|}{$($ mean $=20)$} \\
\hline $0-9$ & $29,769 *$ & $85 \% *$ & $10,052 *$ & $65 \% *$ & $4445 *$ & $58 \% *$ & 133 & $20 \%$ \\
\hline $10-14$ & 3778 & $11 \%$ & 1996 & $13 \%$ & 1099 & $14 \%$ & 125 & $18 \%$ \\
\hline $15-19$ & 637 & $2 \%$ & 952 & $6 \%$ & 636 & $8 \%$ & $117 *$ & $17 \% *$ \\
\hline $20+$ & 935 & $3 \%$ & 2506 & $16 \%$ & 1490 & $19 \%$ & 307 & $45 \%$ \\
\hline
\end{tabular}

* Median values.

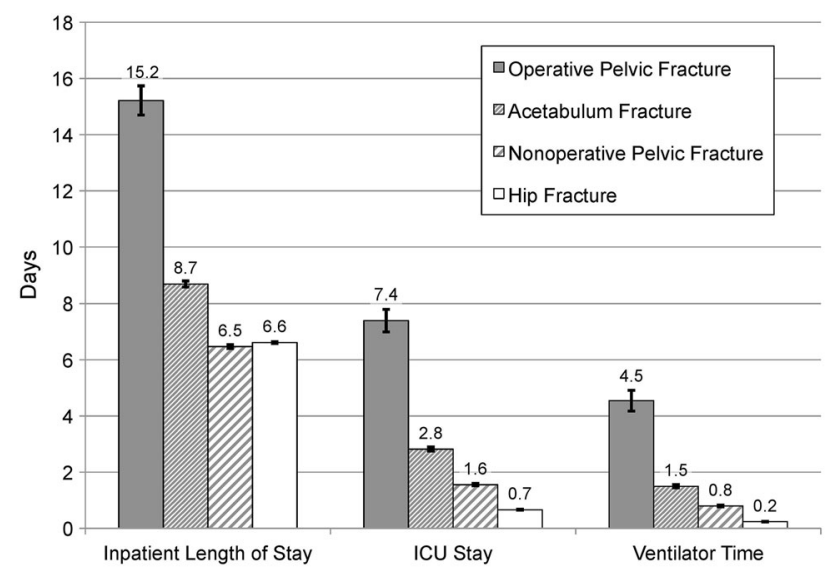

Fig. 1 Mean length of stay, inpatient care unit (ICU) stay, and mechanical ventilation time vary among patients in each subgroup of DRG 536. The error bars represent the SD of the mean.

Mean length of stay for patients with hip fractures was 6.6 days (SD, 5.1 days), and this difference from the mean length of stay for patients with operative pelvic fractures was statistically significant after controlling for patient and hospital factors (difference, 7.7 days; 95\% CI, 7.0-8.4; $\mathrm{p}<$ 0.001) (Table 2). Patients with nonoperative pelvic fractures had a mean length of stay of 6.5 days ( $\mathrm{SD}, 8.2$ days), and this difference from the mean length of stay for patients with operative pelvic fractures was statistically significant after controlling for patient and hospital factors (difference, 8.0 days; 95\% CI, 7.3-8.6; $p<0.001$ ). Patients with acetabulum fractures had a mean length of stay of 8.7 days (SD, 9.5 days), and this difference from the mean length of stay for patients with operative pelvic fractures was statistically significant after controlling for patient and hospital factors (difference, 6.0 days; 95\% CI, 5.4-6.8; $\mathrm{p}<$ $0.001)$.

\section{ICU Stay}

Patients with operative pelvic fractures had the longest mean ICU stay at 7.4 days (SD, 10.5 days) (Fig. 1). Mean ICU stay for patients with hip fractures was 0.7 days (SD, 2.7 days), and this difference from the mean ICU stay for patients with operative pelvic fractures was statistically significant after controlling for patient and hospital factors (difference, 6.3 days; 95\% CI, 5.9-6.7; p $<0.001$ ) (Table 3). Patients with nonoperative pelvic fractures had a mean ICU stay of 1.6 days (SD, 4.7 days), and this difference from the mean ICU stay for patients with operative pelvic fractures was statistically significant after controlling for patient and hospital factors (difference, 5.4 days; 95\% CI, 5.0-5.8; p < 0.001). Patients with acetabulum fractures had a mean ICU stay of 2.8 days (SD, 6.4 days), 
Table 2. Multivariate analysis of inpatient length of stay

\begin{tabular}{|c|c|c|c|}
\hline Variable & $\begin{array}{l}\text { Mean length } \\
\text { of stay } \\
\text { Days (SD) }\end{array}$ & $\begin{array}{l}\text { Difference from } \\
\text { operative pelvic fractures } \\
\text { Days }(95 \% \mathrm{CI})\end{array}$ & $\begin{array}{l}\text { Multivariate } \\
\mathrm{p} \text { value }\end{array}$ \\
\hline \multicolumn{4}{|l|}{ Subpopulations of DRG 536} \\
\hline Hip fracture & $6.6(5.1)$ & $7.7(7.0-8.4)$ & $<0.001$ \\
\hline Nonoperative pelvic fracture & $6.5(8.2)$ & $8.0(7.3-8.6)$ & $<0.001$ \\
\hline Acetabulum fracture & $8.7(9.5)$ & $6.0(5.4-6.8)$ & $<0.001$ \\
\hline Operative pelvic fracture & $15.2(13.6)$ & Reference & - \\
\hline $\begin{array}{l}\text { Patient and hospital factors } \\
\text { (controlled for in multivariate analysis) }\end{array}$ & & $\begin{array}{l}\text { Regression coefficient, } \\
\text { Days }(95 \% \mathrm{CI})\end{array}$ & $\mathrm{p}$ value \\
\hline \multicolumn{4}{|l|}{ Charlson Comorbidity Index } \\
\hline 3 & & Reference & \\
\hline 4 & & $-0.5(-0.7$ to -0.3$)$ & $<0.001$ \\
\hline 5 & & $-0.1(-0.4$ to 0.1$)$ & 0.190 \\
\hline $6+$ & & $0.4(0.2-0.6)$ & 0.001 \\
\hline \multicolumn{4}{|l|}{ Hospital teaching status } \\
\hline Nonteaching & & Reference & \\
\hline University & & $1.4(1.3-1.6)$ & $<0.001$ \\
\hline Community & & $0.4(0.2-0.5)$ & $<0.001$ \\
\hline \multicolumn{4}{|l|}{ Hospital size (beds) } \\
\hline$\leq 200$ & & Reference & \\
\hline $201-400$ & & $0.5(0.3-0.7)$ & $<0.001$ \\
\hline $401-600$ & & $1.0(0.8-1.2)$ & $<0.001$ \\
\hline$>600$ & & $1.4(1.2-1.7)$ & $<0.001$ \\
\hline \multicolumn{4}{|l|}{ Geographic region } \\
\hline Northeast & & Reference & \\
\hline Midwest & & $0.39(0.2-0.6)$ & $<0.001$ \\
\hline South & & $0.49(0.4-0.6)$ & $<0.001$ \\
\hline West & & $0.21(0.0-0.4)$ & 0.016 \\
\hline
\end{tabular}

DRG = Diagnosis Related Group.

and this difference from the mean ICU stay for patients with operative pelvic fractures was statistically significant after controlling for patient and hospital factors (difference, 4.3 days; $95 \%$ CI, 3.9-4.8; $\mathrm{p}<0.001$ ).

\section{Ventilator Time}

Patients with operative pelvic fractures had the longest mean ventilator time at 4.5 days (SD, 9.7 days) (Fig. 1). Mean ventilator time for patients with hip fractures was 0.2 days (SD, 1.9 days), and this difference from mean ventilator time for patients with operative pelvic fractures was statistically significant after controlling for patient and hospital factors (difference, 3.9 days; 95\% CI, 3.6-4.2; $\mathrm{p}<$ 0.001) (Table 4). Patients with nonoperative pelvic fractures had a mean ventilator time of 0.8 days (SD, 3.9 days), and this difference from mean ventilator time for patients with operative pelvic fractures was statistically significant after controlling for patient and hospital factors (difference, 3.4 days; 95\% CI, 3.1-3.7; p < 0.001). Patients with acetabulum fractures had a mean ventilator time of 1.5 days (SD, 5.1 days), and this difference from the mean ventilator time for patients with operative pelvic fractures was statistically significant after controlling for patient and hospital factors (difference, 2.8 days; 95\% CI, 2.5-3.2; $\mathrm{p}<$ $0.001)$.

\section{Discussion}

The current Medicare Acute Inpatient Prospective Payment System determines reimbursement for inpatient admissions by categorizing patients into 746 MS-DRGs that are 
Table 3. Multivariate analysis of ICU length of stay

\begin{tabular}{|c|c|c|c|c|}
\hline Variable & $\begin{array}{l}\text { Mean ICU stay } \\
\text { Days (SD) }\end{array}$ & \multicolumn{2}{|c|}{$\begin{array}{l}\text { Difference from operative pelvic fractures } \\
\text { Days }(95 \% \mathrm{CI})\end{array}$} & Multivariate $\mathrm{p}$ value \\
\hline \multicolumn{5}{|l|}{ Subpopulations of DRG 536} \\
\hline Hip fracture & $0.7(2.7)$ & & & $<0.001$ \\
\hline Nonoperative pelvic fracture & $1.6(4.7)$ & & & $<0.001$ \\
\hline Acetabulum fracture & $2.8(6.4)$ & & & $<0.001$ \\
\hline Operative pelvic fracture & $7.4(10.5)$ & & & - \\
\hline \multicolumn{3}{|c|}{ Patient and hospital factors (controlled for in multivariate analysis) } & $\begin{array}{l}\text { Regression coefficient } \\
\text { Days }(95 \% \mathrm{CI})\end{array}$ & \\
\hline \multicolumn{5}{|l|}{ Charlson Comorbidity Index } \\
\hline 3 & & & Reference & \\
\hline 4 & & & $-0.4(-0.6$ to -0.3$)$ & $<0.001$ \\
\hline 5 & & & $-0.4(-0.5$ to -0.2$)$ & $<0.001$ \\
\hline $6+$ & & & $-0.3(-0.4$ to -0.3$)$ & $<0.001$ \\
\hline \multicolumn{5}{|l|}{ Hospital teaching status } \\
\hline Nonteaching & & & Reference & \\
\hline University & & & $0.9(0.8-1.0)$ & $<0.001$ \\
\hline Community & & & $0.1(0.0-0.2)$ & 0.012 \\
\hline \multicolumn{5}{|l|}{ Hospital size (beds) } \\
\hline$\leq 200$ & & & Reference & \\
\hline $201-400$ & & & $0.2(0.0-0.3)$ & 0.005 \\
\hline $401-600$ & & & $0.4(0.2-0.5)$ & $<0.001$ \\
\hline$>600$ & & & $0.7(0.5-0.8)$ & $<0.001$ \\
\hline \multicolumn{5}{|l|}{ Geographic region } \\
\hline Northeast & & & Reference & \\
\hline Midwest & & & $-0.3(-0.4$ to -0.2$)$ & $<0.001$ \\
\hline South & & & $0.1(0.02-0.2)$ & 0.017 \\
\hline West & & & $0.3(0.2-0.4)$ & $<0.001$ \\
\hline
\end{tabular}

ICU = intensive care unit; DRG = Diagnosis Related Group.

revised annually. Inpatient admissions under the same DRG are reimbursed with the same prospective, "bundled" payment, regardless of actual hospital costs. Currently, DRG 536 (fractures of the hip and pelvis) includes a broad spectrum of orthopaedic injuries, from low-energy fragility fractures of the hip to high-energy acetabulum and pelvic fractures. With the absolute incidence of fractures in the elderly expected to increase dramatically owing to the growing elderly population $[9,17]$ and the high costs of managing these injuries, any substantial variation in costs may result in over- or under-reimbursement to certain hospitals, based on their percentage of high-energy versus low-energy fractures treated in elderly patients. Excess financial strain on these hospitals treating patients with high-energy trauma might result in trauma center closures or shifts away from managing high-energy trauma, resulting in reduced access for these patients. Similar discrepancies between hospital costs and Medicare reimbursements have been seen with other Medicare DRGs $[5,7]$. The results of our study show that, even after controlling for patient and hospital factors, there were important differences in various measures of resource utilization between the four subgroups of Medicare DRG 536. These differences indicate that hospitals currently are receiving under- or over-reimbursement for certain subgroups, depending on their baseline reimbursement for DRG 536. In particular, these increases in resource utilization were most striking for patients with the fractures more likely to be associated with higher-energy mechanisms (operative pelvic fractures and acetabulum fractures).

The primary limitation of this study stems from this exclusion of true cost figures. Standard methods of healthcare cost estimation have important limitations. Cost measurement using charges or cost-to-charge ratios estimates only total costs, and not the marginal costs of 
Table 4. Multivariate analysis of mechanical ventilator days

\begin{tabular}{|c|c|c|c|c|}
\hline \multirow{2}{*}{$\begin{array}{l}\text { Variable } \\
\text { Subpopulations of DRG } 536\end{array}$} & \multirow[t]{2}{*}{$\begin{array}{l}\text { Mean mechanical ventilation time } \\
\text { Days (SD) }\end{array}$} & \multicolumn{2}{|c|}{$\begin{array}{l}\text { Difference from operative pelvic fractures } \\
\text { Days }(95 \% \mathrm{CI})\end{array}$} & \multirow[t]{2}{*}{$\mathrm{p}$ value } \\
\hline & & & & \\
\hline Hip fracture & $0.2(1.9)$ & $3.9(3.6-4.2)$ & & $<0.001$ \\
\hline Nonoperative pelvic fracture & $0.8(3.9)$ & $3.4(3.1-3.7)$ & & $<0.001$ \\
\hline Acetabulum fracture & $1.5(5.1)$ & $2.8(2.5-3.2)$ & & $<0.001$ \\
\hline Operative pelvic fracture & $4.5(9.7)$ & Reference & & - \\
\hline \multicolumn{2}{|c|}{ Patient and hospital factors (controlled for in multivariate analysis) } & Regression coefficient Days (95\% CI) & \multicolumn{2}{|c|}{ Multivariate $p$ value } \\
\hline \multicolumn{5}{|l|}{ Charlson Comorbidity Index } \\
\hline \multicolumn{2}{|l|}{3} & \multicolumn{3}{|l|}{ Reference } \\
\hline \multicolumn{2}{|l|}{4} & $-0.3(-0.4$ to -0.2$)$ & \multicolumn{2}{|l|}{$<0.001$} \\
\hline \multicolumn{2}{|l|}{5} & $-0.3(-0.4$ to -0.2$)$ & \multicolumn{2}{|l|}{$<0.001$} \\
\hline \multicolumn{2}{|l|}{$6+$} & $-0.3(-0.4$ to -0.2$)$ & \multicolumn{2}{|l|}{$<0.001$} \\
\hline \multicolumn{5}{|l|}{ Hospital teaching status } \\
\hline \multicolumn{2}{|l|}{ Nonteaching } & \multicolumn{3}{|l|}{ Reference } \\
\hline \multicolumn{2}{|l|}{ University } & $0.6(0.5-0.7)$ & \multicolumn{2}{|l|}{$<0.001$} \\
\hline Community & & $0.1(0.1-0.2)$ & \multicolumn{2}{|l|}{$<0.001$} \\
\hline \multicolumn{5}{|l|}{ Hospital size (beds) } \\
\hline \multicolumn{2}{|l|}{$\leq 200$} & \multicolumn{3}{|l|}{ Reference } \\
\hline \multicolumn{2}{|l|}{$201-400$} & $0.0(0.0$ to 0.1$)$ & \multicolumn{2}{|l|}{0.346} \\
\hline \multicolumn{2}{|l|}{$401-600$} & $0.2(0.0-0.2)$ & \multicolumn{2}{|l|}{0.004} \\
\hline$>600$ & & $0.4(0.2-0.5)$ & \multicolumn{2}{|l|}{$<0.001$} \\
\hline \multicolumn{5}{|l|}{ Geographic region } \\
\hline \multicolumn{2}{|l|}{ Northeast } & Reference & & \\
\hline Midwest & & $-0.2(-0.2$ to -0.1$)$ & $<0.001$ & \\
\hline South & & $0.1(0.0-0.2)$ & 0.002 & \\
\hline West & & $0.1(0.1-0.2)$ & 0.001 & \\
\hline
\end{tabular}

DRG = Diagnosis Related Group

services, and ignores cost shifting that occurs regularly in hospital accounting [1, 19]. However, we used various measures of resource utilization as a proxy for costs. With the estimated costs of an inpatient day at USD 1236, an ICU day at USD 2278 to USD 5973, and a day on mechanical ventilation at USD 10,299 [13, 15], the results presented in the current study represent significant differences between subpopulations of DRG 536. An additional limitation of our study is the inability to identify patients with major complications or comorbidities, who might be classified in DRG 535 (fractures of the hip or pelvis with major complications or comorbidities) based on the ICD-9 diagnosis data given in the National Trauma Data Bank. The inability to identify patients with major complications or comorbidities might result in overestimation of resource utilization for the subgroups of DRG 536 that are associated with higher rates of major comorbidities and complications. Higher-energy fractures, associated with greater total burden of bodily injury, also likely may be associated with greater inpatient complications owing to more complex inpatient course and longer length of stay. In addition, lower-energy fractures associated with osteoporosis may be associated with higher rates of comorbidities and complications, owing to poorer overall health status. However, by controlling for Charlson Comorbidity Index, our study showed differences in resource utilization that are independent of age and comorbidities. These differences likely indicate disparities in resource utilization for patients in DRG 535 and DRG 536. Additional study using true cost figures and DRG classifications at a single-institution is warranted to estimate the actual financial burden caused by the large spectrum of patients included in DRG 536.

Another limitation of our study results from the inherent biases associated with using a national dataset such as the National Trauma Data Bank. Although this data bank includes data from more than 900 trauma centers, these data are self-reported by hospitals and accuracy is 
dependent on the accuracy of data submitted from the hospitals. Hospitals may submit incomplete datasets resulting in over- or under representation of certain fracture types. Nevertheless, the large overall size of the dataset allowed statistically significant differences to be identified, despite large disparities in sample size between subpopulations (there were far more hip fractures than operative pelvic fractures). Selection bias is also possible as the dataset, while including data from more 900 US trauma centers, is not necessarily nationally representative. There may be biases toward Levels I and II trauma centers which see greater numbers of patients with high-energy trauma. However, the aim of our study was not to measure the relative incidences of the different subpopulations included in MS-DRG 536, but rather to compare how resource utilization varies among patients with these different subpopulations. By controlling for hospital factors, such as hospital size, teaching status, and geographic region, we attempted to control for local variations in resource utilization and isolate the differences in utilization attributable to the various injury types. Another type of bias that may be present is transfer bias, as a percentage of patients in the National Trauma Data Bank have incomplete data regarding inpatient length of stay, ICU stay, or ventilator time. These patients were excluded from the analysis. Of a total of 69,055 patients in MS-DRG 536 and 65 years or older in the National Trauma Data Bank, 10,078 were excluded owing to incomplete data regarding inpatient length of stay $(n=478)$, ICU stay $(n=7484)$, or ventilator time $(n=8534)$ resulting in the 58,977 patients ultimately analyzed. It may be that patients with more severe acute injuries and complicated inpatient courses represent a higher percentage of these patients with incomplete data, biasing the current study results. However, in a post hoc analysis the mean Injury Severity Score for these excluded patients was 9.9 compared with 10.6 for the patients who were analyzed. This difference of 0.7 in Injury Severity Score, while statistically significant $(\mathrm{p}<$ 000.1) owing to the large sample size, was not clinically significant.

Previous studies in the field of orthopaedics showed similar differences in inpatient costs and resource utilization between primary and revision total joint arthroplasties $[6,7]$. At the time of these studies, primary and revision arthroplasties were grouped under Medicare DRG 209 (lower extremity arthroplasty). An initial multicenter cohort study showed differences in operative time, use of allograft, length of stay, and costs, between almost 8000 patients undergoing either primary or revision hip and knee arthroplasties [6]. A subsequent study at one institution showed mean differences in hospital costs of more than USD 7000 per patient between patients having revision and primary arthroplasties [7]. These studies ultimately supported efforts by the American Association of Orthopaedic Surgeons, the American Association of Hip and Knee Surgeons, and the Hip Society to propose modification of the DRG to the Centers for Medicare \& Medicaid Services (CMS), and in 2005, two new DRGs were created: DRG 544 (primary hip and knee replacement) and DRG 545 (revision hip and knee replacement) [5]. Similar efforts with DRG 536 should be pursued next with analysis of true cost figures. This should be conducted in one institution because comparing hospital costs among multiple institutions becomes complicated owing to varying cost accounting practices. In addition, further investigation of other MS-DRGs that include a broad spectrum of orthopaedic patients may be warranted. One such example is DRG 563, which includes all fractures, sprains, strains, and dislocations, excluding those of the femur, hip, and pelvis.

A secondary finding of the current study was the associations of patient and hospital factors with resource utilization. As expected, increased Charleston Comorbidity Index is associated with increased costs, likely attributable to increased resources necessary to treat patients with worse overall health status. We also found that larger hospitals and university hospitals were associated with increased utilization. This would be expected as more critically injured patients often are seen in larger, university-associated trauma centers. A previous study showed worse outcomes for hip fractures managed at teaching hospitals compared with nonteaching hospitals, suggesting more severely injured patients [2]. In addition, a previous study specifically showed there was increased resource utilization in university hospitals compared with community teaching hospitals for patients treated with tissue plasminogen activator for stroke [12]. The geographic differences observed have not been described, to the best of our knowledge, but likely result from regional variations in hospital practices and physician customs for inpatient discharge and ICU transfer.

Now may be an opportune time for CMS to reevaluate classification of DRG 536 because the Medicare DRG system may soon see more-expanded use. As part of the Patient Protection and Affordable Care Act, the CMS Bundled Payments for Care Improvement Initiative will test new bundled-payment delivery models aimed at reducing costs and improving quality of care [22]. Three of the four proposed models currently being tested expand bundling of payments to include services outside inpatient hospital care, including physician services and postacute care services. All four models use the current MS-DRG system to categorize patients. The American Association of Hip and Knee Surgeons has created a bundled payment task force to identify issues in the system specific to hip and knee surgeons and to aid in the eventual transition [8, 18]. In addition, many private health plans, which cover 
patients of all ages, use a MS-DRG-based model for reimbursement. However, as low-energy fragility fractures are less common in younger patients we would expect less variation in resource utilization between patients with hip or pelvis fractures, all of which would more likely result from higher-energy mechanisms. Similar measures should be taken throughout the field of orthopaedic surgery, including in orthopaedic trauma, which sees more than two million elderly patients with fragility fractures annually [11].

Our study showed considerable variation in resource utilization for hospital admissions owing to hip or pelvis fractures, which are reimbursed equally under DRG 536. With the current multitiered US trauma system, it is likely that some trauma centers treat a higher proportion of patients with the more the resource-intensive injuries, resulting in higher costs and lower financial margins. Appropriate reimbursement of hospital services is essential for maintaining patient access to inpatient care in the currently shifting US healthcare landscape. Therefore, creating a separate MS-DRG for operative pelvic fractures and acetabulum fractures would likely help reduce this financial strain. Further comparison of true cost figures at one institution may be a suitable next step to show clear financial benefits of regulatory changes. Just as new healthcare standards and quality benchmarks are being developed in the field of orthopaedics to meet the Patient Protection and Affordable Care Act guidelines, the classification of Medicare DRGs for orthopaedic diagnoses such as hip and pelvic fractures, also warrant reevaluation.

\section{References}

1. Alvin MD, Miller JA, Lubelski D, Rosenbaum BP, Abdullah KG, Whitmore RG, Benzel EC, Mroz TE. Variations in cost calculations in spine surgery cost-effectiveness research. Neurosurg Focus. 2014;36:E1.

2. Anderson KL, Koval KJ, Spratt KF. Hip fracture outcome: is there a "July effect"? Am J Orthop (Belle Mead NJ). 2009;38: 606-611.

3. Bohl DD, Basques BA, Golinvaux NS, Miller CP, Baumgaertner MR, Grauer JN. Extramedullary compared with intramedullary implants for intertrochanteric hip fractures: thirty-day outcomes of 4432 procedures from the ACS NSQIP database. J Bone Joint Surg Am. 2014;96:1871-1877.

4. Bohl DD, Fu MC, Golinvaux NS, Basques BA, Gruskay JA, Grauer JN. The "July effect" in primary total hip and knee arthroplasty: analysis of 21,434 cases from the ACS-NSQIP database. J Arthroplasty. 2014;29:1332-1338.

5. Bozic K. CMS changes ICD-9 and DRG codes for revision TJA. AAOS Bulletin. 2005. Available at: http://www2.aaos.org/ bulletin/jun05/fline1.asp. Accessed February 2, 2016.

6. Bozic KJ, Durbhakula S, Berry DJ, Naessens JM, Rappaport K, Cisternas M, Saleh KJ, Rubash HE. Differences in patient and procedure characteristics and hospital resource use in primary and revision total joint arthroplasty: a multicenter study. J Arthroplasty. 2005;20(7 suppl 3):17-25.

7. Bozic KJ, Katz P, Cisternas M, Ono L, Ries MD, Showstack J. Hospital resource utilization for primary and revision total hip arthroplasty. J Bone Joint Surg Am. 2005;87:570-576.

8. Bozic KJ, Ward L, Vail TP, Maze M. Bundled payments in total joint arthroplasty: targeting opportunities for quality improvement and cost reduction. Clin Orthop Relat Res. 2014;472:188193.

9. Brauer CA, Coca-Perraillon M, Cutler DM, Rosen AB. Incidence and mortality of hip fractures in the United States. JAMA. 2009;302:1573-1579.

10. Browner BD, Jupiter JB, Krettek C, Anderson PA, eds. Skeletal Trauma: Basic Science, Management and Reconstruction. Philadelphia, PA: Saunders; 2009.

11. Burge R, Dawson-Hughes B, Solomon DH, Wong JB, King A, Tosteson A. Incidence and economic burden of osteoporosis-related fractures in the United States, 2005-2025. J Bone Miner Res. 2007;22:465-475.

12. Caveney AF, Silbergleit R, Frederiksen S, Meurer WJ, Hickenbottom SL, Smith RW, Scott PA. Resource utilization and outcome at a university versus a community teaching hospital in tPA treated stroke patients: a retrospective cohort study. BMC Health Serv Res. 2010;10:44.

13. Cooper LM, Linde-Zwirble WT. Medicare intensive care unit use: analysis of incidence, cost, and payment. Critical Care Med. 2004;32:2247-2253.

14. D'Hoore W, Bouckaert A, Tilquin C. Practical considerations on the use of the Charlson comorbidity index with administrative data bases. J Clin Epidemiol. 1996;49:1429-1433.

15. Dasta JF, McLaughlin TP, Mody SH, Piech CT. Daily cost of an intensive care unit day: the contribution of mechanical ventilation. Crit Care Med. 2005;33:1266-1271.

16. Fetter RB, Shin Y, Freeman JL, Averill RF, Thompson JD. Case mix definition by diagnosis-related groups. Med Care. 1980;18(2 suppl):iii, 1-53.

17. Friedman SM, Mendelson DA. Epidemiology of fragility fractures. Clin Geriatr Med. 2014;30:175-181.

18. Froimson MI, Rana A, White RE Jr, Marshall A, Schutzer SF, Healy WL, Naas P, Daubert G, Iorio R, Parsley B. Bundled payments for care improvement initiative: the next evolution of payment formulations: AAHKS Bundled Payment Task Force. $J$ Arthroplasty. 2013;28(8 suppl):157-165.

19. Haley RW. Measuring the costs of nosocomial infections: methods for estimating economic burden on the hospital. Am J Med. 1991;91:32S-38S.

20. Mayes R. The origins, development, and passage of Medicare's revolutionary prospective payment system. J Hist Med Allied Sci. 2007;62:21-55.

21. Nandyala SV, Marquez-Lara A, Fineberg SJ, Singh K. Perioperative characteristics and outcomes of patients undergoing anterior cervical fusion in July: analysis of the "July effect". Spine (Phila Pa 1976). 2014;39:612-617.

22. Rana AJ, Bozic KJ. Bundled payments in orthopaedics. Clin Orthop Relat Res. 2015;473:422-425.

23. Samuel AM, Bohl DD, Basques BA, Diaz-Collado PJ, Lukasiewicz AM, Webb ML, Grauer JN. Analysis of delays to surgery for cervical spinal cord injuries. Spine (phila Pa 1976). 2015; 40:992-1000.

24. Samuel AM, Grant RA, Bohl DD, Basques BA, Webb ML, Lukasiewicz AM, Diaz-Collado PJ, Grauer JN. Delayed surgery after acute traumatic central cord syndrome is associated with reduced mortality. Spine (Phila Pa 1976). 2015;40:349-356. 